\title{
A new benzothiadiazine derivative, LN 5330: effects on pancreatic hormones
}

\author{
D. Hillaire-Buys, G. Ribes, J. P. Blayac and M. M. Loubatières-Mariani
}

Faculté de Médecine, Laboratoire de Pharmacologie et Pharmacodynamie, Equipe de Recherche Associée au CNRS n 786, Institut de Biologie, Montpellier, France

\begin{abstract}
Summary. LN 5330 is a new benzothiadiazine which is a structural analogue of diazoxide. Its effects in vivo were studied on blood glucose levels and insulin, glucagon and somatostatin secretion in normal dogs, and in vitro on glucagon and insulin secretion from the isolated perfused rat pancreas. The results were compared with those obtained with diazoxide at equimolar dose or concentration. In the normal anaesthetized dog having a T-shaped catheter inserted in the pancreaticoduodenal vein, the infusion of $\mathrm{LN} 5330(87.8 \mu \mathrm{mol} / \mathrm{kg}$ for $20 \mathrm{~min})$ induced (1) a progressive increase in blood glucose levels, (2) a rapid decrease in insulin and somatostatin output rate, (3) an immediate increase in pancreatic glucagon secretion, and (4) a delayed decrease of arterial blood pressure. The equimolar dose of diazoxide provoked the same effects on blood glucose levels, insulin and somatostatin output, but a marked de-
\end{abstract}

crease in glucagon output and in arterial blood pressure. In the isolated rat pancreas perfused with $8.3 \mathrm{mmol} / 1$ glucose, the infusion of LN $5330(440 \mu \mathrm{mol} / 1$ for $30 \mathrm{~min})$ induced a drastic fall in insulin and a rapid and persistent increase in glucagon output. This stimulatory effect on glucagon secretion was not found with diazoxide at equimolar concentration. These findings show that LN 5330 is a substance which is distinct from diazoxide and interesting because of its double action: inhibition of insulin secretion and stimulation of glucagon secretion.

Key words: Benzothiadiazine analogue, LN 5330, diazoxide, glucagon, insulin, somatostatin secretion, dog, isolated perfused rat pancreas.
Chloro-7 trifluoromethyl-6 benzothiadiazine-1,2,4 dioxide-1,1 (LN 5330) is a new benzothiadiazine (Fig.1) which is a structural analogue of diazoxide, a known inhibitor of insulin secretion. We have shown previously that LN 5330, like diazoxide, strongly inhibits insulin secretion from the isolated perfused pancreas of the rat. However, after ceasing the LN 5330 infusion, we observed a marked increase in insulin output, which was not found with diazoxide [1].

The aim of the present study was to investigate the effects of LN 5330 on pancreatic hormones in the dog in vivo and to compare them with those obtained with diazoxide. Since these revealed that LN 5330 and diazoxide had different effects on glucagon secretion, we investigated whether this difference could be found also in the isolated perfused rat pancreas.<smiles>CC1=Nc2ccc(Cl)cc2S(=O)(=O)N1</smiles>

\section{Diazoxide}<smiles>O=S1(=O)NC=Nc2cc(C(F)(F)F)c(Cl)cc21</smiles>

LN 5330

Fig. 1. Structural formulae of diazoxide (chloro-7 methyl-3 benzothiadiazine-1,2,4 dioxide-1,1) and LN 5330 (chloro-7 trifluoromethyl -6 benzothiadiazine-1,2,4 dioxide-1,1)

\section{Materials and methods}

\section{Animals}

Studies were carried out either in vivo in normal dogs or in vitro on isolated perfused rat pancreas.

\section{Experiments in vivo}

Normal mongrel dogs were used, weighing $15-20 \mathrm{~kg}$. Before experiments, the animals had free access to water and a standard balanced diet (UAR 121, Villemoisson-sur-Orge, France). They were fasted for $18 \mathrm{~h}$ before the experiment. The animals were anaesthetized intravenously with pentobarbital $(30 \mathrm{mg} / \mathrm{kg}$ body weight). After a median laparotomy, a $\mathrm{T}$-shaped catheter was inserted into the pancreaticoduodenal vein. The animals were given heparin intravenously $(5 \mathrm{mg} / \mathrm{kg})$. Venous blood samples wete taken from the $\mathrm{T}$ shaped catheter for measurement of insulin, glucagon and somatostatin levels. Blood glucose was recorded continuously by an autoanalyzer (Technicon, Chauncey, New York, USA) and arterial pressure with a Ludwig's manometer (Boulitte, Paris, France). A by-pass, inserted in the femoral artery, allowed continuous recording of the arterial $\mathrm{pH}$ (ISIS $4000 \mathrm{pH}$ meter, Tacussel, Lyon, France). LN 5330 and diazoxide were infused at an equimolar dose of $87.8 \mu \mathrm{mol} / \mathrm{kg}$ over a period of $20 \mathrm{~min}(25 \mathrm{mg} / \mathrm{kg}$ body weight for LN 5330 and $20 \mathrm{mg} / \mathrm{kg}$ body weight for diazoxide).

\section{Experiments in vitro}

Pancreases were taken from Wistar rats weighing approximately $350 \mathrm{~g}$ and fed ad libitum. The animals were anaesthetized intraperitoneally with sodium pentobarbital $(60 \mathrm{mg} / \mathrm{kg}$ body weight) and pancreases were isolated and perfused as described previously [2]. The pan- 

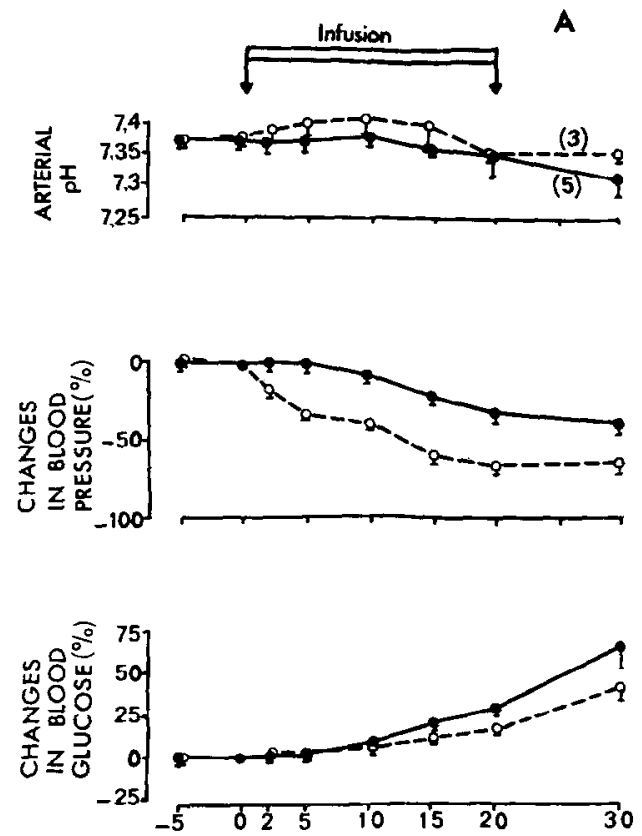

Time (min)

creases were isolated from all neighbouring tissues and organs, particularly from the spleen, stomach and duodenum. The perfusion medium was a Krebs-Ringer bicarbonate buffer containing purified bovine albumin $(2 \mathrm{~g} / \mathrm{l})$. A mixture of oxygen (95\%) and carbon dioxide $(5 \%)$ was bubbled through the medium at atmospheric pressure. The $\mathrm{pH}$ of the solution was 7.35. In all experiments there was an equilibration period of $30 \mathrm{~min}$. At the end of this period, the first sample used for glucagon and insulin assay was collected. Two more samples were taken 10 and $15 \mathrm{~min}$ later for reference samples. In a first set of experiments, the mean glucose concentration in the medium was $8.3 \mathrm{mmol} / 1$ throughout the experiment and LN 5330 or diazoxide was infused for $30 \mathrm{~min}$ at an equimolar concentration of $440 \mu \mathrm{mol} / 1(125 \mathrm{mg} / 1$ for LN 5330 and $101 \mathrm{mg} / 1$ for diazoxide). In a second set of experiments, after $45 \mathrm{~min}$ perfusion with $8.3 \mathrm{mmol} / 1$ glucose, the pancreases were perfused with a physiological medium containing $5.6 \mathrm{mmol} / 1 \mathrm{glu}-$ cose; LN 5330 was administered at $440 \mu \mathrm{mol} / 1$. Control pancreases were infused under the same conditions with $\mathrm{NaCl}(0.154 \mathrm{~mol} / 1)$.

\section{Methods}

Blood glucose values were recorded with an autoanalyzer (Technicon, Chauncey, New York, USA) by a potassium ferricyanide procedure on haemolyzed blood [3]. Insulin was measured by the method of Hales and Randle [4]. The standards used were pure dog insulin and pure rat insulin whose biological potencies were $22 \mu \mathrm{U} / \mathrm{ng}$ and $19 \mu \mathrm{U} / \mathrm{ng}$, respectively. Glucagon was determined by the method of Unger et al. [5], using the $30 \mathrm{~K}$ antiserum which is relatively specific for pancreatic glucagon. Plasma somatostatin was evaluated by a method using $80 \mathrm{C}$ antiserum (a gift from Dr. R. Unger, Dallas, Texas), and tracer (a gift from Clin-Midy Laboratories, Montpellier, France). The procedure has been described previously [6]. Hormonal output rate in experiments in vivo and in vitro was determined by multiplying the concentration of hormone $(\mathrm{ng} / \mathrm{ml}$ or $\mathrm{pg} / \mathrm{ml}$ ) by the liquid flow $(\mathrm{ml} / \mathrm{min})$; in experiments in vivo the venous blood flow was corrected using haematocrit values.

\section{Drugs}

LN 5330 (mol. wt. 284.6) was kindly supplied by Laroche-Navarron Laboratories, Puteaux, France and diazoxide (mol. wt. 230.7) by Schering, Bloomfield, New Jersey, USA. Both drugs were dissolved in an equimolar amount of $\mathrm{NaOH}(1 \mathrm{~mol} / \mathrm{l})$ and the volumes adjusted with $\mathrm{NaCl}(0.154 \mathrm{~mol} / \mathrm{l})$.

\section{Statistical analysis}

Results are expressed as a percentage of the reference value and as mean $\pm S E M$. The results were submitted to analysis of variance using the multiple comparison test [7].

\section{Results}

\section{Experiments in vivo}

In anaesthetized dogs (Fig. 2) the infusion of LN 5330 and diazoxide did not change the arterial $\mathrm{pH}$. Only after $5 \mathrm{~min}$ did LN 5330 induce a progressive decrease in blood pressure $(-32 \%$ at the end of infusion; $p<$ $0.001)$. The infusion of diazoxide induced a drastic fall in blood pressure from $\min 2(p<0.005)$ to $-67 \%$ at the end of infusion. From min 10 , blood glucose levels increased progressively; at the end of the experiments the values were respectively: $+72 \%$ and $+45 \%$ for LN 5330 and diazoxide $(p<0.001)$.

Insulin output decreased from 2 min of LN 5330 infusion (at $20 \mathrm{~min}$ the fall was $-85 \% ; p<0.001$ ). Diazoxide also caused a marked fall in insulin output $(-68 \%$ at $20 \mathrm{~min} ; p<0.001)$. Reductions in insulin secretion, induced by both substances, were not significantly different from each other.

LN 5330 induced an immediate and marked increase of glucagon output. This increase was significant at $\min 2(+92 \%, p<0.001)$ and at $\min 5(+72 \%$, $p<0.05$ ) of the infusion, but disappeared by $10 \mathrm{~min}$. In contrast, with diazoxide the glucagon secretion fell immediately $(p<0.005$ at $5 \mathrm{~min})$; this decrease was $-70 \%$ from min 10 and persisted throughout the experiment.

Pancreaticoduodenal somatostatin output was considerably reduced by both substances $(p<0.001 ; 41 \%$ 

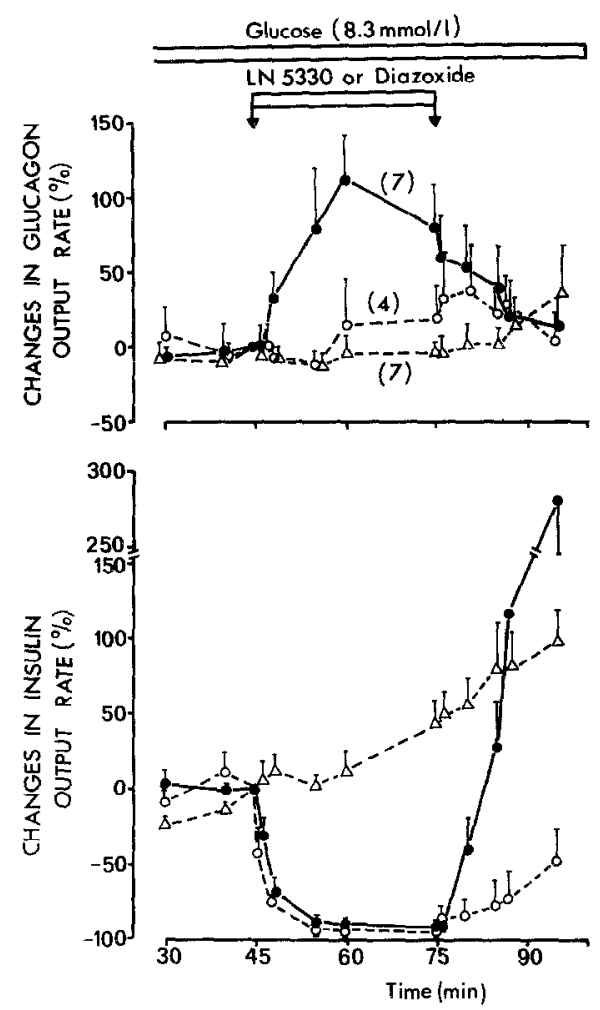

Fig. 3. Changes in glucagon and insulin output rates from isolated rat pancreas perfused with $\mathrm{LN} 5330(-\mathbf{O})$ or diazoxide $(\mathrm{O} \ldots \mathrm{O})$ at a concentration of $440 \mu \mathrm{mol} / 1$ versus control experiments $(\Delta \cdots-\Delta)$. Glucose concentration in the perfusion medium was $8.3 \mathrm{mmol} / 1$. At $45 \mathrm{~min}$, the reference value of glucagon output for LN 5330 experiments was $250 \pm 50 \mathrm{pg} / \mathrm{min}$; diazoxide experiments $232 \pm 40 \mathrm{pg} / \mathrm{min}$; control experiments $257 \pm 30 \mathrm{pg} / \mathrm{min}$. The reference value of insulin ouput rate for LN 5330 experiments was $37 \pm 8$ $\mathrm{ng} / \mathrm{min}$; diazoxide experiments $52 \pm 12 \mathrm{ng} / \mathrm{min}$; control experiments $44 \pm 6 \mathrm{ng} / \mathrm{min}$. The number of experiments is indicated in parentheses

with LN $5330,60 \%$ with diazoxide at $\min 20$ ). These reductions were not significantly different from each other.

\section{Experiments in vitro}

Effects of LN 5330 or diazoxide on glucagon and insulin secretion in the presence of glucose $(8.3 \mathrm{mmol})$. During the LN 5330 infusion at $440 \mu \mathrm{mol} / 1$, a significant increase in glucagon output was observed $(p<0.005)$ (Fig.3). The increase in glucagon secretion occurred at $3 \mathrm{~min}$, and reached $+111 \%$ at $15 \mathrm{~min}$, persisting throughout the infusion. When ceasing the infusion, glucagon output progressively regressed to starting values and was not significantly different from controls. Diazoxide infused at equimolar concentration did not significantly modify glucagon output compared with control pancreas.

The infusion of LN 5330 or diazoxide at the equimolar dose of $440 \mu \mathrm{mol} / 1$ considerably inhibited insulin secretion $(p<0.001)$. This inhibition persisted beyond the infusion period of diazoxide, whereas it disappeared immediately after the infusion of LN 5330 . Moreover with LN 5330, insulin secretion markedly increased $(+275 \%$ of initial output $)$.
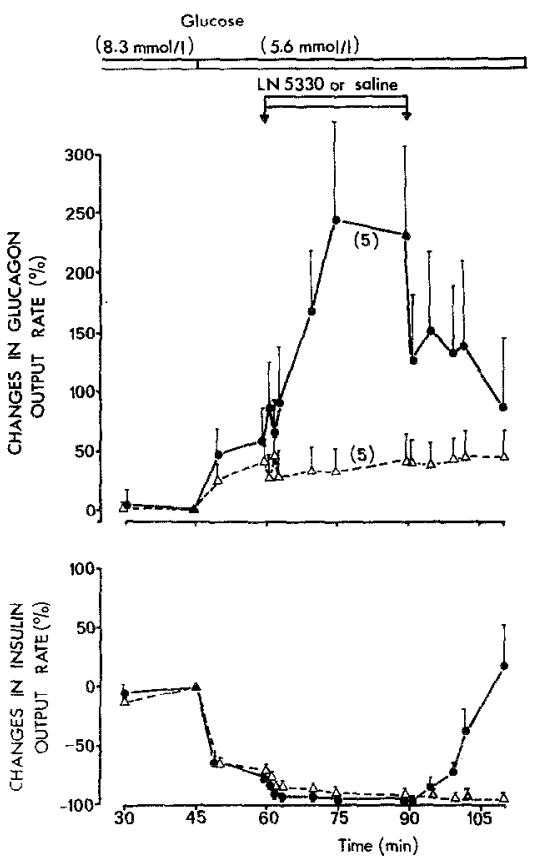

Fig,4. Changes in glucagon and insulin output rates from isolated pancreas perfused with LN $5330(-\ldots)$ at a concentration of $440 \mu \mathrm{mol} / 1$ versus control experiments $(\Delta-\cdots \Delta)$. Glucose concentration in the perfusion medium was $8.3 \mathrm{mmol} / 1$ from 0 to $45 \mathrm{~min}$, and $5.6 \mathrm{mmol} / 1$ from 45 to $110 \mathrm{~min}$. At $45 \mathrm{~min}$ the reference value of glucagon output for LN 5330 experiments was $184 \pm 36 \mathrm{pg} / \mathrm{min}$; control experiments $202 \pm 14 \mathrm{pg} / \mathrm{min}$. The reference value of insulin output for LN 5330 experiments was $36 \pm 2 \mathrm{ng} / \mathrm{min}$; control experiments $47 \pm 7 \mathrm{ng} / \mathrm{min}$. The number of experiments is indicated in parentheses

Effect of LN 5330 on glucagon and insulin secretion in the presence of glucose ( $5.6 \mathrm{mmol} / \mathrm{l})$. Lowering glucose concentration from 8.3 to $5.6 \mathrm{mmol} / 1$ significantly increased glucagon secretion $(p<0.05)$ and inhibited insulin secretion $(p<0.001)$ (Fig. 4). When LN 5330 was added to the perfusion medium, a clear increase of glucagon output, significant from min 10 compared with secretion in control pancreas $(p<0.05)$ was observed.

LN 5330 did not significantly change the fall in insulin secretion induced by the low glucose concentration. After ceasing LN 5330 infusion, the inhibition of insulin secretion disappeared, and at $20 \mathrm{~min}$ insulin reached values comparable to those obtained in the presence of glucose $(8.3 \mathrm{mmol} / 1)$.

\section{Discussion}

Our experiments in vivo show that LN 5330, a new benzothiadiazine derivative and structural analogue of diazoxide, evokes simultaneous inhibition of insulin and stimulation of glucagon secretion. Both effects are accompanied by a progressive increase in circulating blood glucose level. The insulin stimulatory effect previously observed in vitro after stopping LN 5330 [1] was 
not seen in vivo; a possible explanation is that LN 5330 persists in the dog after stopping the infusion.

In the anaesthetized dog, the infusion of LN 5330 causes a fall in arterial blood pressure. However, this effect, which occurred only after the first 5 min of infusion, was progressive and clearly less important than the hypotension due to diazoxide at an equimolar dose. It has been shown that the hyperglycaemic effect of diazoxide is due, not only to inhibition of insulin secretion, but also to glycogenolysis secondary to adrenaline release [8]. LN 5330 did not modify the arterial blood pressure for the first $5 \mathrm{~min}$, so it is suggested that the early increase in glucagon secretion is not due to a release of catecholamines in response to hypotension. The possibility of reflex adrenergic activation even prior to manifest hypotension might be put forward. In this case, a rapid increase in blood glucose level due to glycogenolysis would occur, and an increase in glucagon secretion should be observed also with diazoxide. Furthermore, the increase in glucagon secretion observed in vivo with LN 5330 is confirmed in vitro on the isolated rat pancreas perfused in the presence of 8.3 or $5.6 \mathrm{mmol} / \mathrm{l}$ glucose. These findings indicate that the enhancement of glucagon secretion is due to a direct action of LN 5330 on the pancreas. The stimulating action on glucagon secretion was not found in the experiments with diazoxide. On the contrary, diazoxide produced inhibition of pancreatic glucagon in our experiments in the dog. These results are in accordance with those also obtained in dogs by Samols et al. [9] and Altszuler et al. [10]. The action of diazoxide on glucagon secretion is less clear in other species such as rat [11] or man [12].

It is now accepted that diazoxide reduces the ionized calcium content of the cells of isolated Islets of Langerhans. Recent studies have allowed us to observe an identical phenomenon with LN 5330 [13]. As it has been reported that calcium deprivation in the medium induces an increase of glucagon secretion [14, 15], diazoxide, like LN 5330, would be expected to provoke an increase of glucagon secretion. The results reported up until now show that diazoxide has never induced an increase of glucagon secretion. It is therefore highly improbable that the glucagon stimulatory effect of LN 5330 is directly related to a decrease in cytosolic ionized calcium.

In dogs, the infusions of diazoxide or LN 5330 provoked a marked decrease in the venous pancreaticoduodenal somatostatin output. With respect to LN 5330, this drop might be responsible, in part, for the increase in glucagon secretion. This hypothesis seems unlikely since diazoxide, which also inhibits pancreatic somatostatin secretion, did not increase, but decreased glucagon secretion.

Our present experiments show that $\mathrm{LN} 5330$ has dual effects on pancreatic hormones: inhibition of insulin and stimulation of glucagon secretion. Furthermore, upon withdrawal of LN 5330 from the perfusion medium during in vitro experiments, an increase in insulin release was observed, which was not the case after withdrawal of diazoxide.

In conclusion, these findings indicate that LN 5330, which is a structural analogue of diazoxide and also induces inhibition of insulin secretion, has other distinct and interesting properties.

Acknowledgements. The expert technical assistance of Mrs. M.F.Courty, Mr. R.Puech, Mr. R. Assie and Mr. Y.Gueorguieff is gratefully acknowledged.

\section{References}

1. Blayac JP, Ribes G, Buys D, Puech R, Loubatières-Mariani MM (1981) Effects of a new benzothiadiazine derivative, LN 5330 on insulin secretion. Arch Int Pharm Therap 253: 154-163

2. Loubatières A, Mariani MM, De Malbose H, Ribes G, Chapal J (1969) Etude expérimentale d'un nouveau sulfamide hypoglycémiant particulièrement actif, le HB 419 ou glibenclamide. I. Action bêtacytotrope et insulino-sécrétrice. Diabetologia 5:1-10

3. Alric R, Mariani MM, Loubatières A (1965) Importance de l'état des éléments figurés du sang et en particulier de celui des globules rouges sur les valeurs du glucose sanguin mesuré par l'autoanalyseur Technicon. Path Biol 13: 506-511

4. Hales CN, Randle PJ (1963) Immunoassay of insulin with insulin antibody precipitate. Biochem J 68:137-146

5. Unger RH, Aguilar-Parada E, Müller W, Eisentraut AM (1970) Studies of pancreatic alpha cell function in normal and diabetic subjects. J Clin Invest 49: 837-848

6. Ribes G, Trimble ER, Blayac JP, Wollheim CB, Puech R, Loubatières-Mariani MM (1981) Effect of a new hypoglycaemic agent (HB 699) on the in vivo secretion of pancreatic hormones in the dog. Diabetologia 20: 501-505

7. Zar JH (1974) Biostatistical Analysis. Prentice Hall, Englewood Cliffs, New Jersey, USA, p 151

8. Loubatières A, Mariani MM, Alric R (1968) The action of diazoxide on insulin secretion, medulloadrenal secretion and the liberation of catecholamines. Ann NY Acad Sci 150: 226-241

9. Samols E, Harrison J (1975) Suppression of glucagon secretion by diazoxide. Clin Res 23:330 (Abstract)

10. Altszuler N, Hampshire J, Moraru E (1977) On the mechanism of diazoxide-induced hyperglycemia. Diabetes 26:931-935

11. Urdanivia E, Pek S, Santiago JC (1979) Inhibition of glucagon secretion by diazoxide in vitro. Diabetes $28: 26-31$

12. Roe TF, Kogut MD (1982) Idiopathic leucine sensitive hypoglycemia syndrome: insulin and glucagon responses and effects of diazoxide. Pediatric Res 16:1-4

13. Manteghetti $M$, Puech $R$, Ribes $G$, Blayac JP, Loubatières-Mariani MM (1984) Effect of LN 5330 on insulin release and calcium uptake by isolated rat islets of Langerhans. Comparison with diazoxide. Arch Int Pharmacodyn Ther (in press)

14. Leclercq-Meyer V, Rebolledo O, Marchand J, Malaisse WJ (1976) Glucagon release: paradoxical stimulation by glucose during calcium deprivation. Science 189: 897-899

15. Kawazu S, Ikeuchi M, Kikuchi M, Kanazawa Y, Fujimoto Y, Kosaka K (1981) Dual effects of veratridine on glucagon and insulin secretion. Diabetes 30:446-450

Received: 16 March 1984

and in revised form: 10 July 1984

Professeur M. M.Loubatières-Mariani

Laboratoire de Pharmacologie

Institut de Biologie

Boulevarde Henri IV

F-34060 Montpellier Cedex

France 